Document downloaded from:

http://hdl.handle.net/10251/102696

This paper must be cited as:

Torres-Roca, E.; Fombuena, V.; Vallés Lluch, A.; Ellingham, T. (2017). Improvement of mechanical and biological properties of Polycaprolactone loaded with Hydroxyapatite and Halloysite Nanotubes. Materials Science and Engineering C. 75:418-424.

doi:10.1016/j.msec.2017.02.087

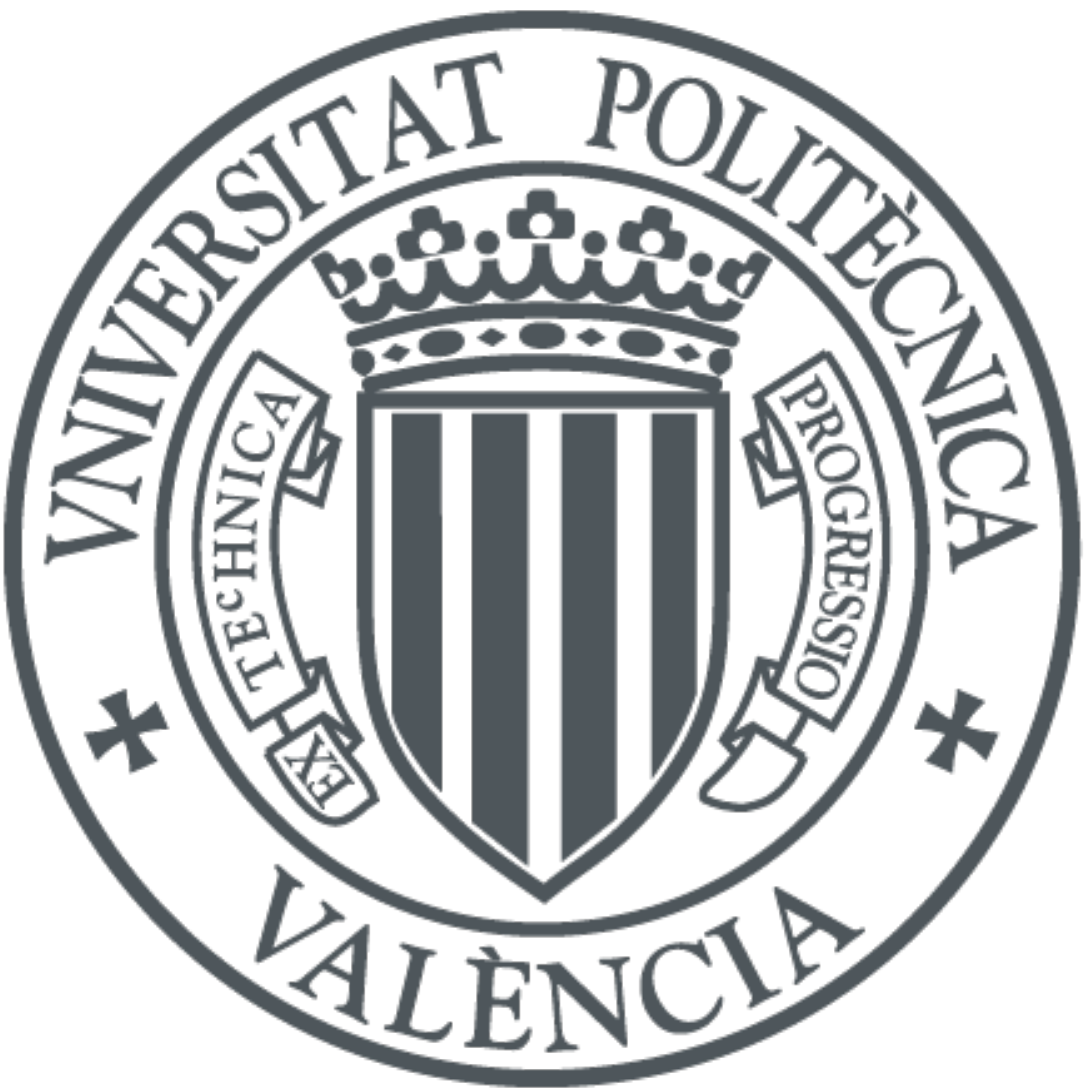

The final publication is available at

http://doi.org/10.1016/j.msec.2017.02.087

Copyright Elsevier

Additional Information 


\title{
Improvement of mechanical and biological properties of Polycaprolactone loaded with Hydroxyapatite and Halloysite Nanotubes
}

\author{
Torres, E. ${ }^{(1,2)}$, Fombuena, $V^{1}{ }^{(1)}$, Vallés-Lluch, A. ${ }^{(2)}$, Ellingham, T. ${ }^{(3)}$ \\ (1) Instituto de Tecnología de Materiales (ITM), \\ Universitat Politècnica de València (UPV) \\ Plaza Ferrándiz y Carbonell, s/n, 03801 Alcoy, Spain \\ (2) Centre for Biomaterials and Tissue Engineering \\ Universitat Politècnica de València \\ Camí de Vera, s/n - 46022 Valencia, Spain \\ (3) BIONATES Laboratory \\ Wisconsin University, Madison \\ 33N Orchard St, Wi 53715
}

\begin{abstract}
Hydroxyapatite (HA) and Halloysite nanotubes (HNTs) percentages have been optimized in Polycaprolactone (PCL) polymeric matrices to improve mechanical, thermal and biological properties of the composites, thus, to be applied in bone tissue engineering or as fixation plates. Addition of HA guarantees a proper compatibility with human bone due to its osteoconductive and osteoinductive properties, facilitating bone regeneration in tissue engineering applications. Addition of HNTs ensures the presence of tubular structures for subsequent drug loading in their lumen, of molecules such as curcumin, acting as controlled drug delivery systems. The addition of $20 \%$ of HA and different amounts of HNTs leads to a substantial improvement in mechanical properties with values of flexural strength up to $40 \%$ over raw PCL, with an increase in degradation temperature. DMA analyses showed stability in mechanical and thermal properties, having as a result a potential composite to be used as tissue engineering scaffold or resorbable fixation plate.
\end{abstract}

Keywords: Polycaprolactone, Hydroxyapatite, Halloysite, Curcumin, Tissue Engineering

\footnotetext{
${ }^{1}$ Corresponding author: Fombuena, V. Email: vifombor@upv.es
} 


\section{Introduction}

Skull injuries are the most frequent traumas found in urban trauma centers [1, 2], increasing the risk of stroke, which is one of the leading causes of death and disability worldwide [3]. Elderly people are the group most affected by craniofacial injuries, due to normal aging and decreased estrogen production, which can lead to bone loss and osteoporosis, the latter being especially prominent in women after menopause [4]. According to the National Institute on Aging (US Department of Health and Human Services), an estimated $8.1 \%$ percent of the world's population was over 61 years old in 2014. By 2050, this number is expected to triple. Accordingly, large efforts are being focused on the research of novel bioabsorbable materials capable of fulfilling the requirements for bone fracture remodeling as a promising alternative to current metal prostheses.

Commonly used metal prostheses are biocompatible and highly resistant to breakage. However, metal prostheses are heavy, expensive, do not promote bone regeneration, nor are degraded over time. Consequently, a second surgery is usually required in order to remove the metal prosthesis once the fractured bone is healed, entailing an extended recuperation process and eventual infections. One of the most significant disadvantages present in metal prostheses is the stress shielding effect caused by a larger support of the load by the plate instead of the bone, yielding a decrease in bone mass and an increase in bone porosity (bone atrophy) [5]. For the purpose of preventing the stress shielding effect, several studies have focused their efforts on the development of low-modulus biodegradable polymers in order to get prosthesis stiffness values similar to that of the host tissue [6-9], resulting in a desirable tissue remodeling.

Osteogenic biomaterials are an alternative to traditional bone repair techniques, leading to faster healing of the involved joint. Materials used for this purpose must be able to overcome important medical issues such as implant rejection, chronic inflammatory reaction, infections, corrosion and metal toxicity (commonly present in typical metallic prostheses) [8, 10]. Natural and synthetic polymers have been broadly studied as fixed systems, bioabsorbable synthetic polymers being the most commonly used, e.g., Polycaprolactone (PCL), Polylactic acid (PLA), and Polyglycolic acid (PGA) [6, 7, 11, $12]$. 
Among them stands out PCL, for its better inflammatory response, slower resorption rate (required to maintain structural properties when used as bone fixation plates) and due to its hydrophobic character [13]. Nonetheless, the mechanical properties are lower compared to other biopolymers such as PLA (PCL flexural modulus is around 0.48-0.58 GPa, while PLA flexural modulus is around 3.1-3.6 GPa). For this reason, the use of PCL as a tissue engineering scaffold, sometimes, need to study possible modifications by adding fillers or blends [14-18]. Few studies have tested PCL composites as internal fixation systems, such as Lowry et al. [13] who prepared fixations of PCL reinforced with glass fiber for rabbit humerus. The results revealed a higher strength for PCL/bone complex compared with bony humerus healed with a stainless steel implant. As such, craniofacial repair fixations appear to be a plausible application for PCL, as it has also been studied by Rudd and co-workers for the last decade [19-23]. In other strategies, PCL scaffolds have been reinforced with Hydroxyapatite (HA) as one of the most common and inexpensive fillers broadly used [24, 25] because it provides osteoconductive properties, causes no inflammatory response, and has very low toxicity in humans [26, 27]. Reinforcement of PCL with different amounts of HA was studied by Biqiong Chen and Kang Sun [28], who reported an enhancement of mechanical properties, reaching the greatest strength value when the concentration of HA was 20\%. Nevertheless, when the content of HA increased over 20\%, the strength decreased significantly. Halloysite Nanotubes (HNTs) have also been used in PCL nanocomposites due to their biocompatibility, high mechanical strength, thermal stability and abundance in nature. PCL polymeric matrices were reinforced with HNTs by Liu et al. [29] and Prashantha et al. [30], who tested the decrease of flexural properties when exceeding $7.5 \mathrm{wt} \%$ of HNTs, correlating the overloading of HNTs with the generation of agglomerates acting as weak points and failure initiation sites. Kang-Suk Lee et al. [31] also studied mechanical properties of PCL/HNTs nanocomposites. The results showed an improvement of tensile strength and modulus of the PCL matrices by the inclusion of HNTs, attributed to the good compatibility between HNTs and PCL. This is due to the formation of strong hydrogen bonding between the hydroxyl groups $(-\mathrm{OH})$ present on the HNT surfaces and carbonyls $(\mathrm{C}=\mathrm{O})$ in the ester linkages of the PCL molecular chains [29]. All these features make HNTs ideal as polymer filler highlighting its nanotubular structure which allows the loading, storage, and controlled release of drugs to be used as a delivery system [32, 33]. 
The introduction of curcumin in HNTs lumen appears promising, being it a commonly used food colorant which possesses excellent pharmacological features such as antioxidative [34], anti-inflammatory [35], anti-tumorigenic [36], in addition to numerous desirable biological benefits [37]. Curcumin is a yellow lipid-soluble natural pigment extracted from the powdered rhizome of the plant Curcuma longa, with the chemical formula [1,7-bis(4-hydroxy-3-methoxyphenyl)-1,6-hepadiene-3,5-dione $\quad[34,38]$. Considerable attention has been paid to curcumin, being one of the most natural compounds studied so far with almost 3000 research articles published regarding its properties [39]. Curcumin has demonstrated to have very low activity in physiological environment owing to its poor solubility in water $(<1 \mu \mathrm{g} / \mathrm{mL})$; besides, it exhibits rapid degradation in alkali conditions (pH 7.4) at physiological temperature [40], which makes curcumin hard to absorb from the gastrointestinal tract after oral administration. Consequently, studies are continuously being developed to achieve appropriate drug delivery systems to enhance in-vivo curcumin stability. Some of these efforts have based on the use of polymer nanospheres of poly (DL-lactide [41, 42] and (NIDAM-NVP(PEG-A)) copolymers [43] as carriers, but also the encapsulation in different biomicrospheres using bovine serum albumin and chitosan [44] or lipid-based nanoparticles [45].

The purpose of this paper is two-fold. Firstly, an optimization of the amount of HA and HNTs loading has been carried out in different blends based on PCL. Previous studies on the reinforcing effect of PCL have been done using HA and HNTs separately, showing both a significant improvement of mechanical properties, but not combined simultaneously to take advantage of their individual suitability. The main objective is to achieve the adequate PCL strength increase and provide osteoconductive properties to be applied in craniofacial fixed systems. In the second part of the work, the functionalization of HNTs has been implemented through the addition of curcumin aiming to confer additional anti-inflammatory properties to the nanohybrids.

\section{Materials and methods}

\subsection{Reagents and materials}

Polycaprolactone (PCL) named commercially as CAPA 6500 was kindly provided by Solvay Interox UK. CAPA 6500 is a high molecular weight thermoplastic linear polyester derived from caprolactone monomer. Its melting point is between $58-60^{\circ} \mathrm{C}$ and its 
molecular weight is $50000 \mathrm{Da}$. Hydroxyapatite $\left(\mathrm{HCa}_{5} \mathrm{O}_{13} \mathrm{P}_{3}\right.$; $\left.\mathrm{HA}\right)$ was supplied by Sigma Aldrich, Madrid, Spain. Halloysite nanotubes (HNTs), with molecular formula $\mathrm{Al}_{2} \mathrm{Si}_{2} \mathrm{O}_{5}$ $(\mathrm{OH})_{4} 2 \mathrm{H}_{2} \mathrm{O}$, were supplied by Sigma Aldrich, Madrid, Spain. Curcumin was supplied by Sigma Aldrich, Madrid, Spain.

\subsection{Preparation of the PCL-based hybrids}

In the first part of the study PCL-based hybrid samples were prepared, varying the mass fraction of HA and HNTs, and characterized to select the inorganic load that optimizes the mechanical properties of the hybrids. The HA and HNTs mass fractions were chosen based, on the one hand, on the work by Biqiong Chen and Kang Sun's [28], who reported an enhancement of mechanical properties when PCL was reinforced with different amounts of HA, the greatest strength value being reached when the concentration of HA was $20 \%$, and noticing a significant strength decrease when the content of HA increased beyond 20\%, and, on the other hand, on the works of Liu et al. [29] and Prashantha et al. [30], who observed an improvement in flexural properties of the polymer matrix loaded with HNTs not exceeding $7.5 \mathrm{wt} \%$. In the latter, the authors correlating the overloading of HNTs with the generation of aggregates acting as weak points and failure initiation sites.

In this first stage, seven different types of hybrids were herein extruded and injection molded, with the mass percentage of HA and HNTs specified in Table 1. Pure PCL samples were used as control. Of these seven hybrids samples, the optimal was chosen in terms of its mechanical and thermal properties, with the aim of studying the influence of HNTs loaded with curcumin on the final properties of the PCL-based hybrids, being reflected in the second stage of the study. Different samples related with both stage of the study are specified in Table 1. 
Table 1. PCL/HA/HNTs mass percent composition for sample injection.

\begin{tabular}{ccccc}
\hline & & \multicolumn{3}{c}{ mass fraction (\%) } \\
\hline 1 & sample ID & PCL & HA & HNTs \\
2 & PCL HA 20 & 80 & 20 & 0 \\
3 & PCL HA 20 HNTs 2,5 & 77.5 & 20 & 2.5 \\
4 & PCL HA 20 HNTs 5,0 & 75 & 20 & 5.0 \\
5 & PCL HA 20 HNTs 7,5 & 72.5 & 20 & 7.5 \\
6 & PCL HNTs 2,5 & 97.5 & 0 & 2.5 \\
7 & PCL HNTs 5,0 & 95 & 0 & 5.0 \\
8 & PCL HNTs 7,5 & 92.5 & 0 & 7.5 \\
\hline 9 & $P C L$ HA20 HNTs7.5 + curcumin & 72.5 & 20 & 0 \\
\hline
\end{tabular}

Firstly, the components of each blend formulation were dried separately in a vacuum oven (PCL at $45^{\circ} \mathrm{C}$ for 24 hours; HA and HNTs at $200^{\circ} \mathrm{C}$ for 48 hours). $600 \mathrm{~g}$ of each manufacturing mixture were next prepared following the percentages specified in Table 1, manually mixed in a zip bag and mechanically mixed in a twin screw corotating extruder at $40 \mathrm{rpm}$, mass dosing of $2.5 \mathrm{Kg} / \mathrm{h}$ and a mass flow rate of $30 \mathrm{Kg} / \mathrm{h}$. The temperature profile for the four extruder zone of the barrels was $65^{\circ} \mathrm{C} / 75^{\circ} \mathrm{C} / 85^{\circ} \mathrm{C} / 90^{\circ} \mathrm{C}$. After this process a room temperature cooling during five minutes was needed before the pelletization of the mixture in a jaw mill at room temperature. The mill used was a jaw crusher BB 300 supplied by Retsch GmbH (Retsch Spain). Samples were injection molded in a Meteor 270/75 injection machine (Mateu and Solé, Barcelona, Spain). The temperature profile of the extruder was $80^{\circ} \mathrm{C} / 80^{\circ} \mathrm{C} / 85^{\circ} \mathrm{C} / 85^{\circ} \mathrm{C} / 90^{\circ} \mathrm{C}$, with a mold temperature of $50^{\circ} \mathrm{C}$ and a cooling time of 6 seconds. The pressure value of the injection molding process was $800 \mathrm{pSi}$ and the mold used was a steel one with mirror finishing with the dimensions recommended by the corresponding standards: strength samples type 1A had dimensions of 170x10x4 $\mathrm{mm}^{3}$ (UNE-EN ISO 527), and flexural samples were 90x10x4 $\mathrm{mm}^{3}$ (ISO 178). 


\subsection{Functionalization of HNTs}

Halloysite nanotubes were functionalized with curcumin before their mixture with PCL and HA in the optimal proportion previously established. The procedure proposed by Abdullayev and Lvov [46] was followed to introduce the curcumin in the nanotubes lumen. Briefly, HNTs powder (10 wt\%) was mixed with a saturated solution of the target compound at room temperature. Water, acetone and ethanol are the most commonly used solvents [32, 47], and were thus herein used to functionalize HNTs. Using polar solvents enhances the loading due to large capillary forces of $200 \mathrm{~atm}$ (as estimated by Laplace formula) pushing the solution into the lumen [48]. Vacuum was applied to the solution containing the active agent, to force the entry of the solution into the nanopores and a partial crystallization of the loaded substance takes place. This process was repeated 3-4 times in order to increase the loading efficiency. After the loading, the halloysite suspension was centrifuged and rinsed with water in order to remove any loosely attached substance from the external walls and remove dissolved excess molecules. Finally, the powder was dried at $80^{\circ} \mathrm{C}$ under vacuum. After functionalization of HNTs with curcumin, those hybrids with the best performance previously established were extruded and injected.

\subsection{Characterization of the samples}

A morphological and thermomechanical characterization of the hybrids was carried out to determine the optimum filler percentage to be introduced in the polymeric matrix. The selected hybrids were then prepared with curcumin-functionalized HNTs and characterized more in depth.

\subsection{Analysis of the solvent with best performance}

TGA measurements, together with SEM images allowed a coarse determination of the amount of curcumin loaded inside HNTs. TGA gave the inorganic mass percentage of different compounds based on degradation temperatures. SEM provided images of the loaded nanotubes where the lumen diameter could be measured.

Scanning Electron Microscopy (SEM) images were obtained to prove the nanotubes dispersion in each matrix as well as to give a qualitative assessment of HNTs loading efficiency. Images were taken in a LEO 1530 FESEM with a $3 \mathrm{kV}$ accelerating voltage 
using an in-lens detector and a working distance of $1.3 \mathrm{~mm}$. Samples were previously gold coated for 30s at 45mA in a Denton Vaccum Desk V sputter coater. All image processing was done with the ImageJ software.

Thermogravimetric Analyses (TGA) were performed to study plausible physical modifications as a consequence of the temperature and determine the mass loss attributed to polymer degradation, to thereby corroborate the percentage of inorganic compound effectively incorporated to the polymeric matrix. The equipment used was a TGA/SDTA 851 (Mettler-Toledo Inc., Schwerzenbach, Switzerland) with a heating rate of $30-350^{\circ} \mathrm{C}$ at $20^{\circ} \mathrm{C} \cdot \mathrm{min}^{-1}$.

\subsection{Mechanical characterization}

Hardness Shore D tests were carried out to measure the resistance of the material towards indentation and correlate the empirical hardness relation with the addition of inorganic compounds to the polymeric matrix. A Model 673-D durometer (J. Bot Instruments, Barcelona, Spain) was used and tests followed the guidelines of the UNEEN ISO 868 norm. Five replicas of each sample were measured to obtain an average value.

Impact Charpy tests were carried out in order to establish the progressive loss in terms of absorbed energy during fracture with the matrix loading. A Charpy pendulum (Metrotec S. A., San Sebastian, Spain) was used for this purpose with an energy of $1 \mathrm{~J}$, according to ISO 179 norm. Each value was obtained with a minimum of 5 notched replicates per composition and calculated as the average, not accepting a deviation above $5 \%$.

Flexural and Tensile tests were performed to establish the material behavior under specific forces, which was required to select the blend formulation in order to fulfill the structural demand for the intended application. Both tests were performed using an electromechanical universal test machine Elib 30 (Ibertest S.A.E, Madrid, Spain). The flexural tests were carried out according to ISO 178 norm with an extension rate of 5 $\mathrm{mm} \cdot \mathrm{min}^{-1}$. In tensile tests, the extension rate was $10 \mathrm{~mm} \cdot \mathrm{min}^{-1}$ according the UNE-EN ISO 527 norm. The flexural and tensile strength (MPa) were determined in each assay.

\subsection{Thermal Characterization}


Differential Scanning Calorimetry (DSC) was used to uncover any physical change in the hybrids and settle subtle temperature variations induced by the addition of inorganic compounds. Measurements were performed in a Mettler-Toledo DSC 821e device (Mettler-Toledo S.A.E., Barcelona, Spain). Each sample consisted in between 5 and 10 mg and was scanned from 30 to 350 at $10^{\circ} \mathrm{C} \cdot \mathrm{min}^{-1}$ under atmospheric air. Results of DSC analysis were studied by the temperature at the melting onset (abbreviate as $T_{m \text {,onset }}$ ), the temperature at the peak maximum (abbreviate as $T_{m, p e a k}$ ) and the heat absorbed per mass unit (abbreviate as $\Delta h_{m}$ ).

VICAT tests were carried out to determine the softening point of the different mixtures, in a Vicat/HDT VHDT 20 device (Metrotec S.A., San Sebastian, Spain). The experiment conditions were those of the standards ISO 306 and D1525.

Heat deflection temperature tests (HDT) were undergone to determine the temperature at which the material deforms under a specific load as a consequence of a controlled temperature increase. The equipment used was a Vicat/HDT VHDT 20 (Metrotec S.A., San Sebastian, Spain). The test was carried out with a load of $200 \mathrm{~g}$ and a temperature program increase of $50^{\circ} \mathrm{C} / \mathrm{h}$, following the ISO 75 and ASTM D648 standards.

Dynamic Mechanical Analyses (DMA) allowed to study the viscoelastic behavior of the materials under stress, to obtain their storage modulus and thus determine the elasticity variation of each hybrid caused by the incorporation of reinforcing fillers into the polymeric matrix. All composites were scanned in an AR G2 device from TA Instruments (TA Instruments, New Castle, USA). The analyses were made in torsion mode with specimens of $40 \times 10 \times 4 \mathrm{~mm}^{3}$. The heating rate was $2^{\circ} \mathrm{C} \cdot \mathrm{min}^{-1}$ from $25^{\circ} \mathrm{C}$ to $80^{\circ} \mathrm{C}$ at a constant frequency of $1 \mathrm{~Hz}$ and a strain of $0.1 \%$ as controlled variable. The storage modulus was obtained as:

$$
E^{\prime}=\frac{\sigma_{0}}{\varepsilon_{0}} \cos \delta
$$

where $\mathrm{E}^{\prime}$ is the storage modulus (MPa), $\sigma$ and $\varepsilon$ are the stress and strain, respectively, and $\delta$ is the phase lag between stress and strain. 


\section{Results and Discussion}

\section{Improvement of PCL mechanical properties with HA and HNTs}

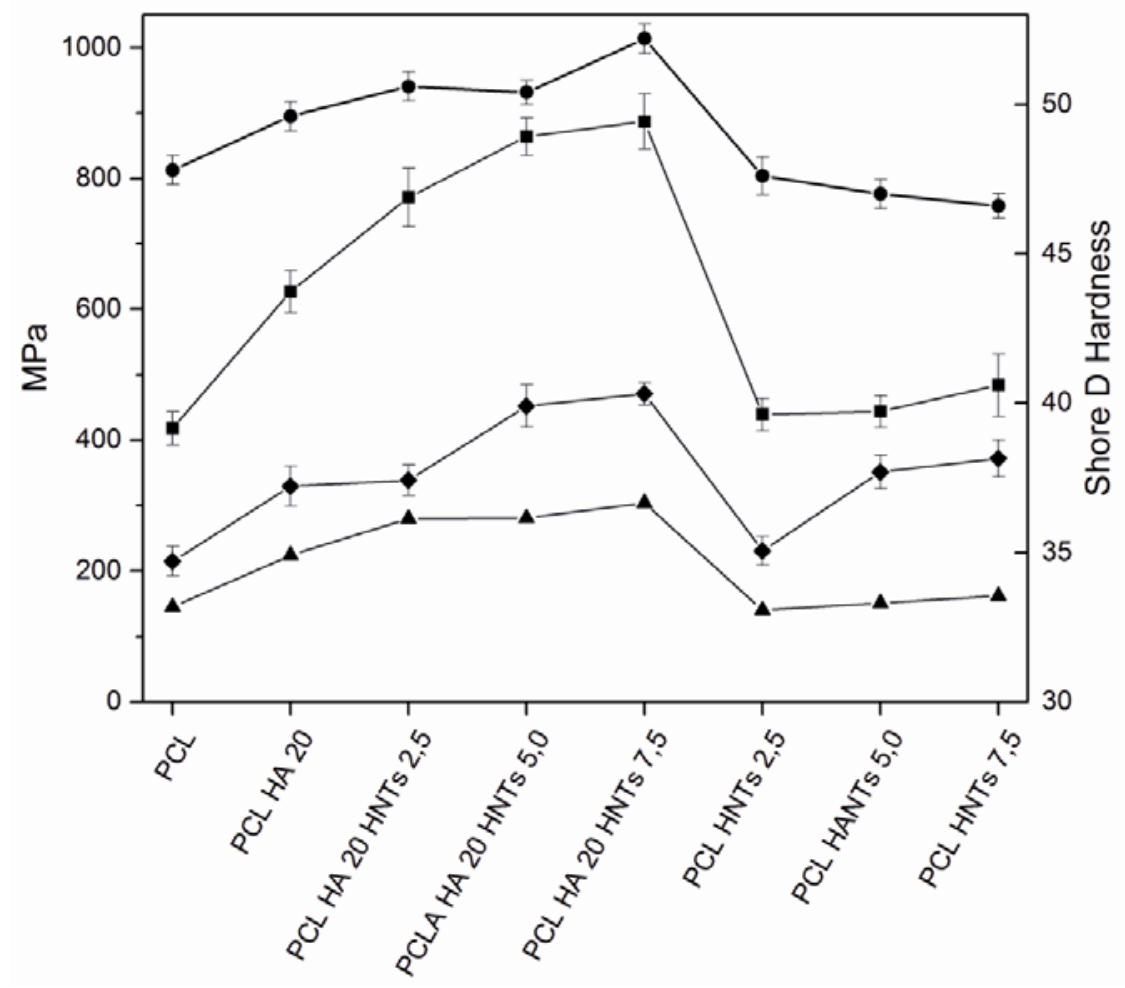

Figure 1. Comparison of mechanical properties of the different nanohybrids and PCL as control. $\longrightarrow$ Storage modulus (MPa), $\longrightarrow$ Young's modulus (MPa), $\longrightarrow-$ Flexural modulus (MPa), —- Shore D Hardness (secondary axis).

Analyzing the data (Figure 1), it is evident that a synergic effect between HA and HNTs in the polymeric matrix occurs. Comparing the results within different samples and PCL raw material, a noticeable improvement of mechanical properties was achieved with the simultaneous addition of the two fillers. If Shore D Hardness value of neat PCL is compared with samples with $20 \%$ of HA and $7.5 \%$ of HNTs, an increase of $10.3 \%$ was obtained (p-value $=0.4$ ). Flexural modulus improved as the HNTs percentage increased, reaching values of up to $112.3 \%$ in samples with $20 \%$ of HA and $7.5 \%$ of HNTs, with a flexural modulus of 886.8 MPa (p-value $=42.1$ ). Young's Modulus was observed to increase to $109.3 \%$ with the addition of the two fillers reaching its greatest value of 449.6 MPa (p-value $=17.12$ ) when 7.5\% of HNTs was added. Dynamic Mechanical Analysis (DMA) at human body temperature, $37^{\circ} \mathrm{C}$, indicates that the addition of HA and HNTs as fillers entails an enhancement of the storage modulus being again the hybrid loaded with 
7.5\% HNTs the material that shows the highest value. On the other side, samples with only HNTs as filler show a decrease in Shore D Hardness average values, with similar flexural and strength results compared to those of raw PCL samples. Hence, the addition of only HNTs does not provide a substantial improvement, but loading PCL with both fillers leads to an enhancement of mechanical properties with 20\% HA and 7.5\% HNTs.

These results suggest that strong interactions between PCL, HA and HNTs occur, allowing a more efficient load transfer [49]. These must be hydrogen bondings between the hydroxyl groups present in the surface of HNTs and the carboxyls present in the ester linkages of the PCL molecular chains [29]. Additionally, it cannot be ruled out that the fillers act to fill the empty spaces between the polymer chains as different authors have suggested [50-52].

Regarding the impact test, it highlights the difference in results as a function of the added filler. In general terms, a reduction of absorbed energy by the polymer is detected, resulting from the introduction of HA and HNTs simultaneously. A PCL unfilled has a toughness of $13.1 \mathrm{~kJ} / \mathrm{m}^{2}$, while as for example, in sample with $20 \%$ of HA and $7,5 \%$ of HNTs the toughness is reduced to $8.0 \mathrm{~kJ} / \mathrm{m}^{2}$. Thus, as expected, the addition of fillers causes a lower toughness of samples. However, an interesting aspect is detectable: in samples with HNTs but not HA, the absorbed energy was greater. For example, samples with 5 or $7.5 \%$ of HNTs have a toughness around $25 \mathrm{~kJ} / \mathrm{m}^{2}$. Therefore, addition of only HNTs induces an increase in the toughness of the sample, possibly due to the tubular shape of HNTs, structure able to absorb energy during impacts.

However, the values of flexural moduli obtained are lower compared to the majority of human bones, as reported in [53]. Nevertheless, the values obtained can be compared with those of human trabecular bone, which is typically between 7000 and $25000 \mathrm{MPa}$, although these values depend on different variables such as type of bone, ages, location, and health factors [54-57].

\section{Modification of thermal properties}



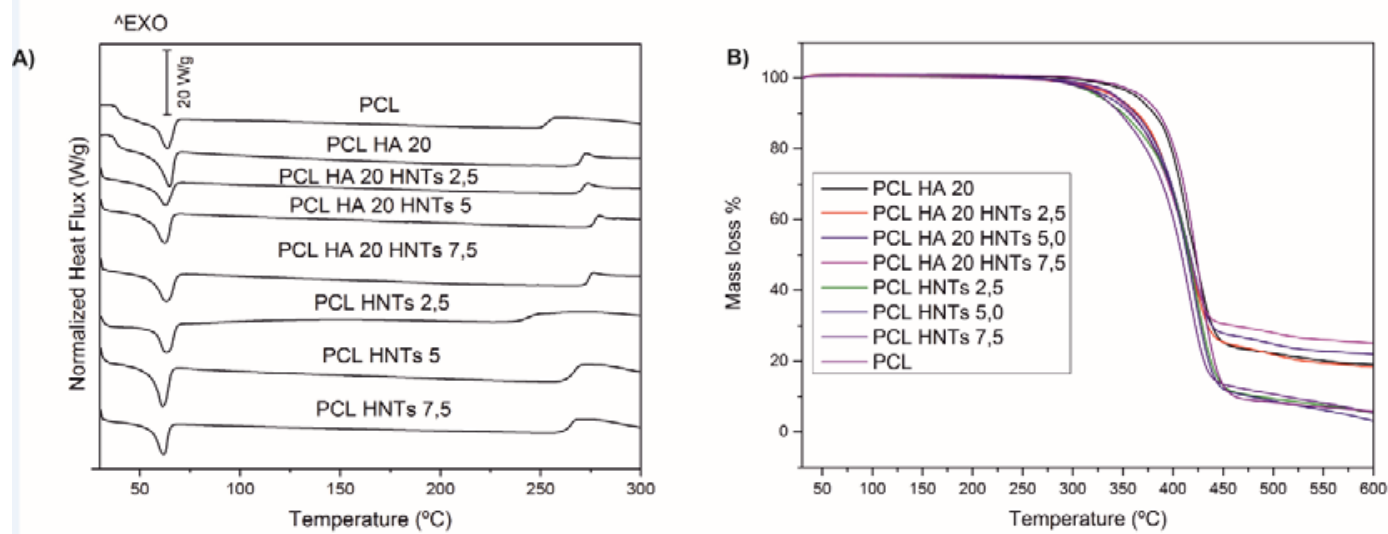

Figure 2. (A) Differential Scanning Calorimetry (DSC) results show the normalized heat flux vs. temperature and.Thermogravimetric analysis (TGA) shows the mass loss (\%) (B)

Heat flux of DSC plots was normalized in order to make the different curves comparable. With the addition of fillers in the PCL matrix, the melting temperature remains almost stable, with a maximum difference of $2^{\circ} \mathrm{C}$ (Figure 2. A). This slight difference does not affect the injection molding processability with the consequent energy saving [58]. However, the addition of HNTs rises the onset of degradation greater when the two fillers are added, reaching values of $274^{\circ} \mathrm{C}$ (Figure 2. B). It provides a great thermal stability range, shifting the start of the main mass loss $20^{\circ} \mathrm{C}$ compared with PCL samples $\left(250^{\circ} \mathrm{C}\right)$. This temperature shift could be explained by a change of simple chain scission degradation process common in raw PCL [59] to a complex two-step nucleation-driven degradation mechanism, which implies the starting of the degradation process at discrete points (where the clay is added) from where it extends to the rest of the polymer [60]. Thus, the thermal decomposition process is delayed due to the slow formation of those discrete points. TGA analyses exhibited, as expected, a residual mass corresponding to the total inorganic load, HA and/or HNTs.

Vicat and HDT data (data not shown) revealed that the temperature change between samples was not greater than $2^{\circ} \mathrm{C}$. For example, value of Vicat Temperature of PCL are $54.3^{\circ} \mathrm{C}$, while that of samples with the highest loading, PCL HA 20 HNTS 7.5, is $54.9^{\circ} \mathrm{C}$. These results do not provide substantial information other than that required to perform an optimum mixing of the material as it was specified in the temperature profile for the four extruder zone of the barrels $\left(65^{\circ} \mathrm{C} / 75^{\circ} \mathrm{C} / 85^{\circ} \mathrm{C} / 90^{\circ} \mathrm{C}\right)$.

\section{Optimization of the HNTs loading with curcumin}




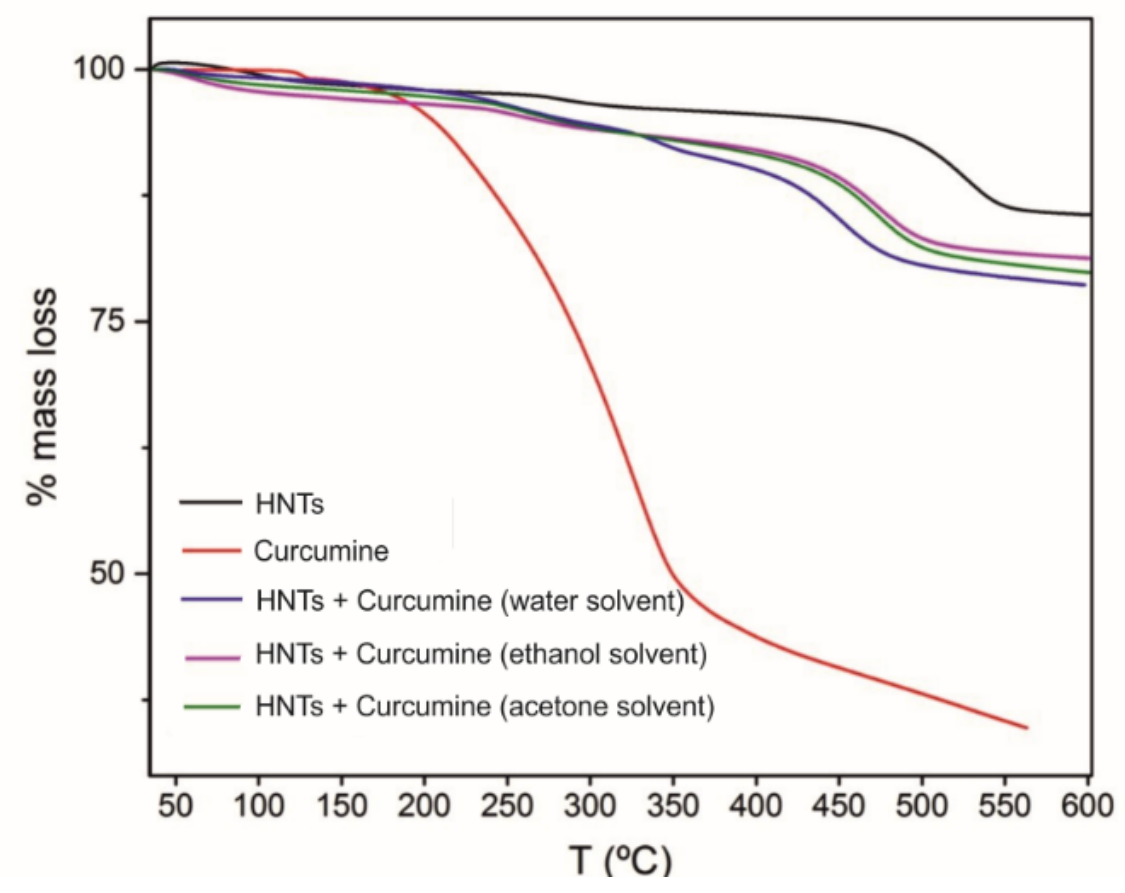

Figure 3. Normalized mass loss vs. temperature of halloysite nanotubes functionalized with curcumin using three different solvents (ethanol, acetone or water).

TGA curves (Figure 3) were obtained up to $600^{\circ} \mathrm{C}$ to determine which of the three solvents used (water, ethanol or acetone) allowed the incorporation of the greatest amount of curcumin inside the HNTs lumen. Two significant mass loss stages are discerned in Figure 3 for all solvents within the same range of temperature and a similar residual mass. The first step, between $210-277^{\circ} \mathrm{C}$ with a mass loss of around $3.5 \%$, is attributed to the thermal descomposition of curcumin, which is known to occur in two overlapped stages [61, 62]: the first one $\left(215-354^{\circ} \mathrm{C}\right)$ represents the degradation of acetone acetaldehyde, while the second $\left(215-469^{\circ} \mathrm{C}\right)$ corresponds to the descomposition of phenyl oxyacetic acid molecules [62]. It is noteworthy to point out that a loading efficiency of merely $10 \%$ wt of nanotubes can be achieved according to literature [63]. The second degradation stage identified for the three solvents, within the temperature range of $413-490^{\circ} \mathrm{C}$ and a mass loss of $12.5 \%$, is due to a combination of thermal descomposition of curcumin and the dehydroxylation of HNTs [64]. Dehydroxylation has been postulated to be analogous to thermal dehydroxylation and degradation of kaloinite due to the symilarity between halloysite and kaloinite structure and chemistry [65], where most of the $\mathrm{OH}$ groups are removed. Although results are quite similar independently of the solvent, HNTs functionalized with acetone exhibit a slightly higher mass loss percentage taking into 
account both steps, which suggests that a greater amount of curcumin is introduced in the HNTs lumen by using acetone as solvent.

Table 2. Comparison of the curcumin loading efficiency in HNTs using different solvents.

\begin{tabular}{|c|c|c|}
\hline Water & Ethanol & Acetone \\
\hline Solubility < $0.1 \mathrm{mg} / \mathrm{ml}$ & Solubility $10 \mathrm{mg} / \mathrm{ml}$ & Solubility $>50 \mathrm{mg} / \mathrm{ml}$ \\
\hline $4.0 \%$ mass loss 1 st step & $3.1 \%$ mass loss 1 st step & $4.5 \%$ mass loss 1 st step \\
\hline $12.5 \%$ mass loss 2 nd step & $12.3 \%$ mass loss 2 nd step & $13 \%$ mass loss 2 nd step \\
\hline
\end{tabular}

SEM images (Table 2) were obtained with the aim of visually assessing the functionalization efficiency corresponding to each solvent. Traces of active agent attached to the outer surface of HNTs cannot be excluded, even though it is difficult to distinguish them. Nonetheless, the same loading procedure was followed by Riela et al. [66] using ethanol as solvent and reported a successful encapsulation. Similar results using poly(amidoamine) dendrimers as container were also reported by Wang et al. [67]. If attention is paid to the inner diameter of the nanotubes in the SEM images, narrower diameters can be observed for HNTs when acetone was used as a solvent, suggesting that curcumin molecules are attached to the inner surface of the nanotubes. These results agree with the solubility of curcumin in each solvent (solubility values in Table 2 were provided by the supplier Sigma Aldrich) and the TGA results, concluding that using acetone as solvent yields the highest amount of curcumin inside the HNTs lumen. The functionalization efficiency can thus be linked to the solubility of curcumin in each solvent. With curcumin being nearly insoluble in water $(<0.1 \mathrm{mg} / \mathrm{ml})$, its concentration in the solution would be small, hence only a small amount of curcumin would be introduced into HNTs lumen using water as solvent. Conversely, with a solubility of $>50$ $\mathrm{mg} / \mathrm{mL}$ in acetone, the amount of curcumin inside the nanotubes is expected to be greater 
for the same dissolution volume compared with those in water or ethanol, the solubility of curcumin in ethanol being $10 \mathrm{mg} / \mathrm{mL}$.

Influence of HNTs loaded with curcumin incorporated to the PCL matrix on its mechanical and thermal properties

Table 3. Mechanical properties of PCL, PCL HA20 HNTs7.5 and PCL HA20 HNTs7.5+ curcumin samples.

\begin{tabular}{|c|c|c|c|}
\hline \multicolumn{4}{|c|}{ Flexural modulus (MPa) } \\
\hline & $P C L$ & PCL HA20 HNTs7.5 & PCL HA2O HNTs7.5 + curcumin \\
\hline average value & 449.5 & 886.8 & 615.9 \\
\hline$p$-value & 20.0 & 37.5 & 3.3 \\
\hline \multicolumn{4}{|c|}{ Young's Modulus (MPa) } \\
\hline average value & 214.8 & 449.6 & 224.9 \\
\hline$p$-value & 18.5 & 17.1 & 4.7 \\
\hline
\end{tabular}

Incorporating HNTs previously loaded with curcumin to PCL provokes a reduction of mechanical properties as compared with those of PCL HA20 HNTs7.5 samples (Table 3). The improvement of flexural modulus with the addition of HA and HNTs to the PCL matrix was 112.3\%. However, when HNTs were functionalized with curcumin, the flexural modulus decreased 30.55\%. Nevertheless, the results obtained for PCL HA20 HNTs7.5 + curcumin are $47.5 \%$ higher than those of pure PCL. A significant reduction of tensile strength was also observed with the addition of curcumin being $50.0 \%$ less than that of PCL HA20 HNTs7.5 samples.

Table 4. Thermal properties of PCL, PCL HA20 HNTs7.5 and PCL HA20 HNTs7.5+curcuminPCL samples.

\begin{tabular}{cccc}
\hline Sample & $T_{m, \text { onset }}\left({ }^{\circ} \mathrm{C}\right)$ & $T_{m, \text { peak }}\left({ }^{\circ} \mathrm{C}\right)$ & $\Delta \boldsymbol{h}_{m}(\mathrm{~J} / \mathrm{g})$ \\
\hline PCL & 54.2 & 58.3 & 54.8 \\
PCL HA20 HNTs7.5 & 53.3 & 60.0 & 40.8 \\
PCL HA20 HNTs7.5 + curcumin & 53.4 & 60.9 & 43.1 \\
\hline
\end{tabular}

The thermal analysis to study the effect of previously loading the HNTs incorporated to PCL with curcumin in comparison with neat PCL and with PCL loaded with HA and 
HNTs (Table 4) revealed an increment of $2.6^{\circ} \mathrm{C}$ in the melting temperature. This effect can be explained by a complex two-step nucleation-driven degradation mechanism induced by the introduction of fillers [60], which appears to provide a greater thermal stability range without affecting the injection molding processability.
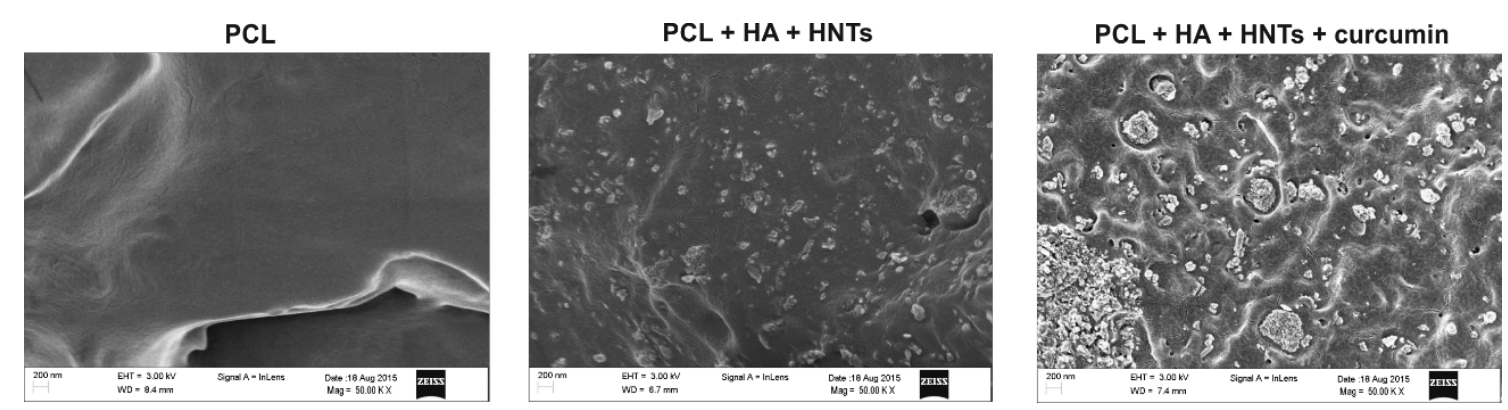

Figure 4. SEM images of PCL, PLA HA20 HNTs7.5 and PLA HA20 HNTs7.5 + curcumin samples, the last two showing HNTs aggregates.

SEM images were taken to qualitatively analyze the morphology of the materials (Figure 4). Clusters with size around $6 \mu \mathrm{m}$ were observed in PCL HA20 HNTs7.5 + curcumin samples, which could explain the loss of mechanical properties (Table 3). Indeed, HNTs aggregates are known to usually act as crack initiation sites leading to sudden failure of the material $[30,68]$. Aggregate formation seems to be accentuated during the drying process after functionalization of HNTs with the consequent reduction of water molecules, resulting in less interactions between them and HNTs [69]. Aggregates of hollow nanotubes are induced by edge to edge and face to edge interactions between HNTs resulting in zig-zag structures [70]. In further works, the aggregates formation could plausibly be avoided by the dispersion of the powder in polar solvents such as acetone, followed by mechanical stirring [71], alternatively or simultaneously to the modification of the HNTs surface [72], and additionally with successive extrusion steps previous to injection molding [68].

\section{Conclusions}

Taking into account that facial trauma is one of the most common injuries seen in urban trauma centers, development of new bioabsorbable materials capable of fulfilling the requirements of bone fracture remodeling is a promising alternative to current metal prostheses. 
Polycaprolactone (PCL) is a degradable biomaterial under physiologic conditions, persisting in vivo for more than one year, fulfilling sufficient high modulus until the regeneration of the broken bone. However, its applications are limited due to its low mechanical properties. For this reason, two fillers have been simultaneously used to modify the PCL strength: Hydroxyapatite (HA) provides osteoconductive properties, yet is neither toxic nor induces inflammatory responses, and Halloysite nanotubes (HNTs) are biocompatible, possess high mechanical strength, and are abundant in nature.

Designing the optimal blend formulations and establishing the procedure to manufacture test specimens was the first objective of this work. A $20 \mathrm{wt} \%$ of HA was kept constant while the percentage of HNTs varied from $2.5 \mathrm{wt} \%$ to $7.5 \mathrm{wt} \%$. The optimal HNTs percentage was determined after mechanical and thermal tests: the materials that showed the best properties compared to bone were those with 5 and $7.5 \mathrm{wt} \%$ of HNTs. Although both materials show similar mechanical properties, a $7.5 \mathrm{wt} \%$ of HNTs was established as the optimum percentage so as to maximize functionalization with curcumin.

In general terms, an increase of more than $10 \%$ in Shore D Hardness was obtained, while than flexural modulus and Young's modulus increased by doubling the values taking as a reference, neat PCL. Considering the improvement of PCL mechanical properties with the addition of $20 \mathrm{wt} \%$ of HA and $7.5 \mathrm{wt} \%$ of HNTs, the implementation of these devices with curcumin in order to give them antioxidant, anti-inflammatory and potentially chemotherapeutic properties was performed. In future studies, these materials could be applied to obtain an osteogenic biomaterial with controlled delivery as an alternative to traditional bone repair techniques that will eventually lead to a faster healing of the involved joint.

HNTs were preferably functionalized with curcumin in an acetone saturate solution because its solubility in this solvent is greater than in others like ethanol or water, and subsequently rinsed in water, dried, mixed and injected with PCL and HA to be mechanically and thermally tested. The results showed that functionalization of HNTs with curcumin entailed a reduction of the mechanical properties of the hybrids. SEM images suggest that the functionalization process provokes the formation of aggregates during the drying process, resulting in the generation of crack initiation sites that promote the failure of the material. Dispersion of functionalized HNTs should thus be further enhanced by using polar solvents followed by mechanical stirring and several extrusion 
processes prior to injection molding to improve the mechanical properties of these nanohybrids.

\section{References}

[1] P. Kelley, M. Crawford, S. Higuera, L.H. Hollier, Two Hundred Ninety-Four Consecutive Facial Fractures in an Urban Trauma Center: Lessons Learned, Plastic and Reconstructive Surgery 116(3) (2005) 42E-49E.

[2] P. Ko, C. Dang, Manual of forensic emergency medicine-a guide for clinicians., London, United Kingdom, 2010.

[3] N. Malli, T. Ehammer, K. Yen, E. Scheurer, Detection and characterization of traumatic scalp injuries for forensic evaluation using computed tomography, International Journal of Legal Medicine 127(1) (2013) 195-200.

[4] S. Khosla, L.J. Melton, B.L. Riggs, Clinical review 144 - Estrogen and the male skeleton, Journal of Clinical Endocrinology \& Metabolism 87(4) (2002) 1443-1450.

[5] Y. Noyama, T. Miura, T. Ishimoto, T. Itaya, M. Niinomi, T. Nakano, Bone Loss and Reduced Bone Quality of the Human Femur after Total Hip Arthroplasty under Stress-Shielding Effects by Titanium-Based Implant, Materials Transactions 53(3) (2012) 565-570.

[6] S. Bose, M. Roy, A. Bandyopadhyay, Recent advances in bone tissue engineering scaffolds, Trends in Biotechnology 30(10) (2012) 546-554.

[7] K. Tuzlakoglu, N. Bolgen, A.J. Salgado, M.E. Gomes, E. Piskin, R.L. Reis, Nano- and micro-fiber combined scaffolds: A new architecture for bone tissue engineering, Journal of Materials Science-Materials in Medicine 16(12) (2005) 1099-1104.

[8] S.N. Kurpad, J.A. Goldstein, A.R. Cohen, Bioresorbable fixation for congenital pediatric craniofacial surgery: A 2-year follow-up, Pediatric Neurosurgery 33(6) (2000) 306-310.

[9] S. Liao, W. Wang, M. Uo, S. Ohkawa, T. Akasaka, K. Tamura, F.Z. Cui, F. Watari, A three-layered nano-carbonated hydroxyapatite/collagen/PLGA composite membrane for guided tissue regeneration, Biomaterials 26(36) (2005) 7564-7571.

[10] M.B. Habal, Triad of system applications for absorbable rigid fixation of the craniofacial skeleton, Journal of Craniofacial Surgery 7(5) (1996) 394-398.

[11] B. Cecen, L.D. Kozaci, M. Yuksel, O. Ustun, B.U. Ergur, H. Havitcioglu, Biocompatibility and biomechanical characteristics of loofah based scaffolds combined with hydroxyapatite, cellulose, poly-L-lactic acid with chondrocyte-like cells, Materials Science \& Engineering CMaterials for Biological Applications 69 (2016) 437-446.

[12] N. Ignjatovic, V. Wu, Z. Ajdukovic, T. Mihajilov-Krstev, V. Uskokovic, D. Uskokovic, ChitosanPLGA polymer blends as coatings for hydroxyapatite nanoparticles and their effect on antimicrobial properties, osteoconductivity and regeneration of osseous tissues, Materials Science \& Engineering C-Materials for Biological Applications 60 (2016) 357-364.

[13] K.J. Lowry, K.R. Hamson, L. Bear, Y.B. Peng, R. Calaluce, M.L. Evans, J.O. Anglen, W.C. Allen, Polycaprolactone/glass bioabsorbable implant in a rabbit humerus fracture model, Journal of Biomedical Materials Research 36(4) (1997) 536-541.

[14] Z. He, J. Liu, J. Jiao, G. Wu, X. Xiao, Fabrication and Characterization of Poly(L-lactic acid)polycaprolactone Composite Nanofiber Scaffolds, Chemical Journal of Chinese UniversitiesChinese 35(10) (2014) 2265-2271. 
[15] S.U. Maheshwari, S.V. Kumar, N. Nagiah, T.S. Uma, Electrospinning of polyvinylalcoholpolycaprolactone composite scaffolds for tissue engineering applications, Polymer Bulletin 70(11) (2013) 2995-3010.

[16] M. Mattioli-Belmonte, G. Vozzi, Y. Whulanza, M. Seggiani, V. Fantauzzi, G. Orsini, A. Ahluwalia, Tuning polycaprolactone-carbon nanotube composites for bone tissue engineering scaffolds, Materials Science \& Engineering C-Materials for Biological Applications 32(2) (2012) 152-159.

[17] C.R. Reed, L. Han, A. Andrady, M. Caballero, M.C. Jack, J.B. Collins, S.C. Saba, E.G. Loboa, B.A. Cairns, J.A. van Aalst, Composite Tissue Engineering on Polycaprolactone Nanofiber Scaffolds, Annals of Plastic Surgery 62(5) (2009) 505-512.

[18] Q. Yao, P. Nooeaid, R. Detsch, J.A. Roether, Y. Dong, O.-M. Goudouri, D.W. Schubert, A.R. Boccaccini, Bioglass (R)/chitosan-polycaprolactone bilayered composite scaffolds intended for osteochondral tissue engineering, Journal of Biomedical Materials Research Part A 102(12) (2014) 4510-4518.

[19] T.J. Corden, I.A. Jones, C.D. Rudd, P. Christian, S. Downes, K.E. McDougall, Physical and biocompatibility properties of poly-epsilon-caprolactone produced using in situ polymerisation: a novel manufacturing technique for long-fibre composite materials, Biomaterials 21 (7) (2000) 713-724.

[20] L. Onal, S. Cozien-Cazuc, I.A. Jones, C.D. Rudd, Water absorption properties of phosphate glass fiber-reinforced poly-epsilon-caprolactone composites for craniofacial bone repair, Journal of Applied Polymer Science 107(6) (2008) 3750-3755.

[21] I. Ahmed, A.J. Parsons, G. Palmer, J.C. Knowles, G.S. Walkers, C.D. Rudd, Weight loss, ion release and initial mechanical properties of a binary calcium phosphate glass fibre/PCL composite, Acta Biomaterialia 4(5) (2008) 1307-1314.

[22] J.E. Gough, P. Christian, C.A. Scotchford, C.D. Rudd, I.A. Jones, Synthesis, degradation, and in vitro cell responses of sodium phosphate glasses for craniofacial bone repair, Journal of Biomedical Materials Research 59(3) (2002) 481-489.

[23] J.E. Gough, P. Christian, J. Unsworth, M.P. Evans, C.A. Scotchford, I.A. Jones, Controlled degradation and macrophage responses of a fluoride-treated polycaprolactone, Journal of Biomedical Materials Research Part A 69A(1) (2004) 17-25.

[24] F. Ghorbani, H. Nojehdehian, A. Zamanian, Physicochemical and mechanical properties of freeze cast hydroxyapatite-gelatin scaffolds with dexamethasone loaded PLGA microspheres for hard tissue engineering applications, Materials Science \& Engineering C-Materials for Biological Applications 69 (2016) 208-220.

[25] Z. Li, B.C. Thompson, Z. Dong, K.A. Khor, Optical and biological properties of transparent nanocrystalline hydroxyapatite obtained through spark plasma sintering, Materials Science \& Engineering C-Materials for Biological Applications 69 (2016) 956-966.

[26] I.T. Jackson, R. Yavuzer, Hydroxyapatite cement: an alternative for craniofacial skeletal contour refinements, British Journal of Plastic Surgery 53(1) (2000) 24-29.

[27] L. Miller, A.B. Guerra, R.S. Bidros, C. Trahan, R. Baratta, S.E. Metzinger, A comparison of resistance to fracture among four commercially available forms of hydroxyapatite cement, Annals of Plastic Surgery 55(1) (2005) 87-92.

[28] B.Q. Chen, K. Sun, Mechanical and dynamic viscoelastic properties of hydroxyapatite reinforced poly(epsilon-caprolactone), Polymer Testing 24(8) (2005) 978-982.

[29] M. Liu, B. Guo, M. Du, Y. Lei, D. Jia, Natural inorganic nanotubes reinforced epoxy resin nanocomposites, Journal of Polymer Research 15(3) (2008) 205-212.

[30] K. Prashantha, M.F. Lacrampe, P. Krawczak, Processing and characterization of halloysite nanotubes filled polypropylene nanocomposites based on a masterbatch route: effect of halloysites treatment on structural and mechanical properties, Express Polymer Letters 5(4) (2011) 295-307. 
[31] K.-S. Lee, Y.-W. Chang, Thermal, mechanical, and rheological properties of poly(epsiloncaprolactone)/halloysite nanotube nanocomposites, Journal of Applied Polymer Science 128(5) (2013) 2807-2816.

[32] Y.M. Lvov, D.G. Shchukin, H. Mohwald, R.R. Price, Halloysite clay nanotubes for controlled release of protective agents, Acs Nano 2(5) (2008) 814-820.

[33] D. Rawtani, Y.K. Agrawal, Multifarious Applications Of Halloysite Nanotubes: A Review, Reviews on Advanced Materials Science 30(3) (2012) 282-295.

[34] A. Goel, A.B. Kunnumakkara, B.B. Aggarwal, Curcumin as "Curecumin": From kitchen to clinic, Biochemical Pharmacology 75(4) (2008) 787-809.

[35] M.M.Y. Chan, H.I. Huang, M.R. Fenton, D. Fong, In vivo inhibition of nitric oxide synthase gene expression by curcumin, a cancer preventive natural product with anti-inflammatory properties, Biochemical Pharmacology 55(12) (1998) 1955-1962.

[36] A. Khar, A.M. Ali, B.V.V. Pardhasaradhi, Z. Begum, R. Anjum, Antitumor activity of curcumin is mediated through the induction of apoptosis in AK-5 tumor cells, Febs Letters 445(1) (1999) 165-168.

[37] B.B. Aggarwal, A. Kumar, A.C. Bharti, Anticancer potential of curcumin: Preclinical and clinical studies, Anticancer Research 23(1A) (2003) 363-398.

[38] R.A. Sharma, A.J. Gescher, W.P. Steward, Curcumin: The story so far, European Journal of Cancer 41(13) (2005) 1955-1968.

[39] P. Anand, A.B. Kunnumakara, C. Sundaram, K.B. Harikumar, S.T. Tharakan, O.S. Lai, B. Sung, B.B. Aggarwal, Cancer is a Preventable Disease that Requires Major Lifestyle Changes, Pharmaceutical Research 25(9) (2008) 2097-2116.

[40] R. Yang, S. Zhang, D. Kong, X. Gao, Y. Zhao, Z. Wang, Biodegradable Polymer-Curcumin Conjugate Micelles Enhance the Loading and Delivery of Low-Potency Curcumin, Pharmaceutical Research 29(12) (2012) 3512-3525.

[41] S.M. Zhang, R.R. Cao, J. Liu, L. Liu, P. Lu, W. Zhou, L. Cheng, P.P. Chen, Q.M. Luo, Fabrication and characterization of biodegradable nanospheres containing curcumin, 2007, pp. 767-770.

[42] R. Masaeli, T.S.J. Kashi, R. Dinarvand, V. Rakhshan, H. Shahoon, B. Hooshmand, F.M. Abbas, M. Raz, A. Rajabnejad, H. Eslami, K. Khoshroo, M. Tahriri, L. Tayebi, Efficacy of the Biomaterials 3 wt\%-nanostrontium-hydroxyapatite-enhanced calcium phosphate cement (nanoSr-CPC) and nanoSr-CPC-incorporated simvastatin-loaded poly(lactic-co-glycolic-acid) microspheres in osteogenesis improvement: An explorative multi-phase experimental in vitro/vivo study, Materials Science \& Engineering C-Materials for Biological Applications 69 (2016) 171-183.

[43] S. Bisht, G. Feldmann, S. Soni, R. Ravi, C. Karikar, A. Maitra, A. Maitra, Polymeric nanoparticle-encapsulated curcumin ("nanocurcumin"): a novel strategy for human cancer therapy, Journal of nanobiotechnology 5 (2007) 3-3.

[44] V. Kumar, S.A. Lewis, S. Mutalik, D.B. Shenoy, Venkatesh, N. Udupa, Biodegradable microspheres of curcumin for treatment of inflammation, Indian journal of physiology and pharmacology 46(2) (2002) 209-17.

[45] K. Sou, S. Inenaga, S. Takeoka, E. Tsuchida, Loading of curcumin into macrophages using lipid-based nanoparticles, International Journal of Pharmaceutics 352(1-2) (2008) 287-293.

[46] E. Abdullayev, Y. Lvov, Halloysite clay nanotubes as a ceramic "skeleton" for functional biopolymer composites with sustained drug release, Journal of Materials Chemistry B 1(23) (2013) 2894-2903.

[47] E. Abdullayev, Y. Lvov, Halloysite Clay Nanotubes for Controlled Release of Protective Agents, Journal of Nanoscience and Nanotechnology 11(11) (2011) 10007-10026.

[48] Y. Lvov, A. Aerov, R. Fakhrullin, Clay nanotube encapsulation for functional biocomposites, Advances in Colloid and Interface Science 207 (2014) 189-198.

[49] K. Prashantha, B. Lecouvet, M. Sclavons, M.F. Lacrampe, P. Krawczak, Poly(lactic acid)/halloysite nanotubes nanocomposites: Structure, thermal, and mechanical properties as a function of halloysite treatment, Journal of Applied Polymer Science 128(3) (2013) 1895-1903. 
[50] A. Kamoun, A. Jelidi, M. Chaabouni, Evaluation of the performance of sulfonated esparto grass lignin as a plasticizer-water reducer for cement, Cement and Concrete Research 33(7) (2003) 995-1003.

[51] J. Mohammadi-Rovshandeh, P. Pouresmaeel-Selakjani, S.M. Davachi, B. Kaffashi, A. Hassani, A. Bahmeyi, Effect of Lignin Removal on Mechanical, Thermal, and Morphological Properties of Polylactide/Starch/Rice Husk Blend Used in Food Packaging, Journal of Applied Polymer Science 131(22) (2014).

[52] M.R. Rahman, M.N. Islam, M.M. Huque, S. Hamdan, A.S. Ahmed, Effect Of Chemical Treatment On Rice Husk (RH) Reinforced Polyethylene (PE) Composites, Bioresources 5(2) (2010) 854-869.

[53] L.F. Charles, M.T. Shaw, J.R. Olson, M. Wei, Fabrication and mechanical properties of PLLA/PCL/HA composites via a biomimetic, dip coating, and hot compression procedure, Journal of Materials Science-Materials in Medicine 21(6) (2010) 1845-1854.

[54] R.B. Ashman, J.Y. Rho, Elastic-Modulus Of Trabecular Bone Material, Journal of Biomechanics 21(3) (1988) 177-181.

[55] D.T. Reilly, A.H. Burstein, V.H. Frankel, Elastic-Modulus For Bone, Journal of Biomechanics 7(3) (1974) 271-\&.

[56] J.Y. Rho, L. Kuhn-Spearing, P. Zioupos, Mechanical properties and the hierarchical structure of bone, Medical Engineering \& Physics 20(2) (1998) 92-102.

[57] P.K. Zysset, X.E. Guo, C.E. Hoffler, K.E. Moore, S.A. Goldstein, Elastic modulus and hardness of cortical and trabecular bone lamellae measured by nanoindentation in the human femur, Journal of Biomechanics 32(10) (1999) 1005-1012.

[58] M. Ranjbar-Mohammadi, S.H. Bahrami, Development of nanofibrous scaffolds containing gum tragacanth/poly (epsilon-caprolactone) for application as skin scaffolds, Materials Science \& Engineering C-Materials for Biological Applications 48 (2015) 71-79.

[59] R. Khiari, Z. Marrakchi, M.N. Belgacem, E. Mauret, F. Mhenni, New lignocellulosic fibresreinforced composite materials: A stepforward in the valorisation of the Posidonia oceanica balls, Composites Science and Technology 71(16) (2011) 1867-1872.

[60] P.E. Sanchez-Jimenez, L.A. Perez-Maqueda, A. Perejon, J.M. Criado, Nanoclay Nucleation Effect in the Thermal Stabilization of a Polymer Nanocomposite: A Kinetic Mechanism Change, Journal of Physical Chemistry C 116(21) (2012) 11797-11807.

[61] Z. Chen, Y. Xia, S. Liao, Y. Huang, Y. Li, Y. He, Z. Tong, B. Li, Thermal degradation kinetics study of curcumin with nonlinear methods, Food Chemistry 155 (2014) 81-86.

[62] F. Jasim, T. Talib, SOME OBSERVATIONS ON THE THERMAL-BEHAVIOR OF CURCUMIN UNDER AIR AND ARGON ATMOSPHERES, Journal of Thermal Analysis 38(11) (1992) 2549-2552.

[63] E. Ruiz-Hitzky, K. Ariga, Y.M. Lvov, Halloysite Nanotubules a Novel Substrate for the Controlled Delivery of Bioactive Molecules, in Bio-Inorganic Hybrid Nanomaterials, Eduardo Ruiz-Hitzky, Katsuhiko Ariga and Yuri M. Lvov, Berlin, London, 2008.

[64] P. Yuan, D. Tan, F. Annabi-Bergaya, W. Yan, M. Fan, D. Liu, H. He, CHANGES IN STRUCTURE, MORPHOLOGY, POROSITY, AND SURFACE ACTIVITY OF MESOPOROUS HALLOYSITE NANOTUBES UNDER HEATING, Clays and Clay Minerals 60(6) (2012) 561-573.

[65] M.E. Smith, G. Neal, M.B. Trigg, J. Drennan, STRUCTURAL CHARACTERIZATION OF THE THERMAL TRANSFORMATION OF HALLOYSITE BY SOLID-STATE NMR, Applied Magnetic Resonance 4(1-2) (1993) 157-170.

[66] S. Riela, M. Massaro, C.G. Colletti, A. Bommarito, C. Giordano, S. Milioto, R. Noto, P. Poma, G. Lazzara, Development and characterization of co-loaded curcumin/triazole-halloysite systems and evaluation of their potential anticancer activity, International Journal of Pharmaceutics 475(1-2) (2014) 613-623.

[67] L. Wang, X. Xu, Y. Zhang, Y. Zhang, Y. Zhu, J. Shi, Y. Sun, Q. Huang, Encapsulation of curcumin within poly(amidoamine) dendrimers for delivery to cancer cells, Journal of Materials ScienceMaterials in Medicine 24(9) (2013) 2137-2144. 
[68] A. Fernandez, M. Muniesa, J. Gonzalez, Characterisation and Processing of Reinforced PA 6 with Halloysite Nanotubes (HNT) for Injection Molding, Strojniski Vestnik-Journal of Mechanical Engineering 59(3) (2013) 183-192.

[69] M. Liu, B. Guo, M. Du, D. Jia, Drying induced aggregation of halloysite nanotubes in polyvinyl alcohol/halloysite nanotubes solution and its effect on properties of composite film, Applied Physics a-Materials Science \& Processing 88(2) (2007) 391-395.

[70] H. Ismail, P. Pasbakhsh, M.N.A. Fauzi, A. Abu Bakar, Morphological, thermal and tensile properties of halloysite nanotubes filled ethylene propylene diene monomer (EPDM) nanocomposites, Polymer Testing 27(7) (2008) 841-850.

[71] Y. Ye, H. Chen, J. Wu, C.M. Chan, Interlaminar properties of carbon fiber composites with halloysite nanotube-toughened epoxy matrix, Composites Science and Technology 71(5) (2011) 717-723.

[72] U.A. Handge, K. Hedicke-Hoechstoetter, V. Altstaedt, Composites of polyamide 6 and silicate nanotubes of the mineral halloysite: Influence of molecular weight on thermal, mechanical and rheological properties, Polymer 51(12) (2010) 2690-2699. 